\title{
The Patient Protection and Affordable Care Act (PPACA)
}

\author{
Terry Jaqua ${ }^{1}$ and Ecler Jaqua ${ }^{2 *}$ \\ ${ }^{1}$ Trident University International, USA \\ ${ }^{2}$ Department of Family Medicine, Loma Linda University, USA
}

*Corresponding author: Ecler Jaqua, Department of Family Medicine, Loma Linda University, 1200 California Street, Suite 240, Redlands, CA 92374. Tel: 909-558-6688, E-mail: ejaqua@llu.edu

Citation: Terry Jaqua, Ecler Jaqua (2019) The Patient Protection and Affordable Care Act (PPACA). J Nurs Healthcare Manage 2: 104

Article history: Received: 19 January 2019, Accepted: 04 February 2019, Published: 06 February 2019

The Patient Protection and Affordable Care Act (PPACA) were signed into law on March 23, 2010. This signing into law ushered a new era in the United States healthcare. The law incorporates elements such as state health insurance Exchanges, individual and employer responsibility provisions, group subsidies to individuals, small employers and Medicaid expansion [1]. The Act has ten legislative Titles that are separate, but that address similar aims. The aims of this Act is to achieve near-universal health care insurance coverage through combined efforts of employers, government and individuals, improve health care coverage's quality, fairness, and affordability, improve efficiency and value of health care, and strengthen access to primary health care through dimensions such as preventive and primary health care availability (Rosenbaum, 2011). The final aim is to invest strategically in the health of the public by expanding community investments and clinical preventive care.

The Patient Protection and Affordable Care Act (PPACA) strengthen minimum coverage such as Medicaid. Under this law, all U.S citizens are expected to have healthcare insurance coverage. The Act aims at expanding existing healthcare insurance coverage, and this will result in fundamental restructuring of Medicaid. This restructuring entails covering all U.S citizens and legal residents whose income is "less than $133 \%$ of the federal poverty level" (Rosenbaum, 2011). In addition, the Act also streamlines Medicaid enrollment. The five-year Medicaid's waiting period for U.S legal residents will still apply to recently enrolled people, but they will qualify for enrollment and tax subsidies via the health insurance exchange [2]. The full implementation of the law will see an increase in the number of Medicaid beneficiaries by around 18 million [2]. This is due to eligibility expansion to include all legal residents who have incomes that are below 133\% of federal poverty level (FPL). Additionally, 2 million people will enroll in Medicaid through employer-sponsored health insurance. The Medicaid coverage will be extended to individuals who are 26 years-old who previously fell under foster care. The financing of Medicaid will be through the Federal Medical Assistance Program (FMAP). The Medicaid health insurance coverage for newly eligible people will be wholly covered by FMAP for the first three years and 90 \% for years that follow. The Federal government will bear a huge proportion of newly eligible enrollees' costs. The Federal expenditures on healthcare will be paid through penalties paid by employers who choose not to offer coverage and individuals who decide to remain uninsured. The total amount of these penalties is projected to reach $\$ 72$ billion by 2019 [2].

The Act attempts to stimulate innovation in healthcare so as to absorb impact in healthcare insurance coverage expansion and changes in funding. Reform initiatives on the delivery system include provisions for hospitals to receive incentive payments from the Federal government that will make hospitals embrace electronic medical records systems, spur meaningful use of Health Information Technology, and utilize e-prescribing (Taylor and Clinchy, 2012). The law has provisions that are intended at spurring technological transitions in Medicare. In addition, the Act creates the Medicare Shared Saving Program (MSSP) specifically for the ACO's. The aim of MSSP is to ensure individuals get better health care, the health of populations is improved, and achieve slower growth in health care costs by making profound improvements in this care. Accountable Care Organizations are expected to be responsible for providing care for a particular population of Medicare beneficiaries. The organizations have an opportunity to share in cost savings with Medicare if they succeed to deliver high-quality care while reducing costs. Moreover, the PPACA brings new funding sources through the Patient-Centered Outcomes Research Institute and the Centre for Medicare and Medicaid Innovation. The two funding sources will provide money for research and innovation grants that will be crucial in developing new care delivery models. The research funds and innovation grants are essential in the modernization of research, education and care approaches (Taylor and Clinchy, 2012). The Patient-Centered Outcomes Research Institute will avail \$500 million each year from 2015 whereas the Centre for Medicare and Medicaid Innovation has a kitty of $\$ 10$ billion to be utilized as innovation grants by Accountable Care Organizations (ACOs). The Act also makes improvements in Medicare services for beneficiaries including medication therapy management programs that will be tasked with prescription drug review, covering individuals exposed to environmental health hazards, and helping beneficiaries learn about their doctors through the 'Physician Compare' website. 
Improving quality and efficiency of healthcare is one of the titles of Patient Protection and Affordable Care Act. The reform initiatives are crucial in measuring the quality of health care that public payers receive and providing reports on its performance. In addition, the reforms will enable public payers to target improvement in the management of health conditions that are serious and chronic so as to prevent frequent hospital admissions or re-admissions. The multi-payer National Quality Strategy that the Act intends to develop is instrumental in generating quality and efficiency measures for many payers, and these measures will promote greater safety, value purchasing, and the availability of extensive health information (Rosenbaum, 2011). The National Quality Strategy to be spearheaded by the HHS Secretary will be crucial in strengthening the health care quality infrastructure that entails service delivery, population health, and patient outcomes [3]. The Act has established the Institute for Comparative Clinical Effectiveness Research that promotes research that is crucial in identifying the most efficient and appropriate means for providing healthcare for very diverse populations. The Act has also led to the establishment of a value-based purchasing program that links Medicare payments to quality performance [3]. This will promote the quality of health and medical care delivery since it will necessitate that Medicare payments be correlated with the quality especially for high-cost conditions.

On utilization and opening up healthcare access, the Act is poised to positively affect the two. The Act has invested in the National Health Service Corps and the extensive expansion of community health centers. Rosenbaum (2011) reports that the value of investments that were to go to community health centers in fiscal year (FY) 2011 to FY 2015 was to total \$11 billion and \$1.5 billion in the National Health Service Corps. The two expansions were expected to double the number of patients served from 20 million in 2010 to about 40 million in 2015 (Rosenbaum, 2011). This change indicates enhanced accessibility of patients to healthcare. The Act has also new Medicaid options to serve those in need of long-term care. The voluntary long-term care insurance program christened the Community Living Assistance Services and Support Act enables those who require long-term care to continuously utilize the healthcare services. Overall, the full implementation of the Act will reduce the number of uninsured Americans by more than $50 \%$. The percentage of Americans who have health care insurance coverage will be about $94 \%$ thus enabling them to access and utilize healthcare services in the country.

The Patient Protection and Affordable Care Act is transformational, and it presents opportunities for extensive advances in public health practice and policy. These opportunities include transforming coverage and care and reforming the public health basic mission in a universal coverage environment

\section{References}

1. Kulshrestha S (2013) From Physician to Patient: the Effects of the Patient Protection and Affordable Care Act(PPACA). Student Pulse 5.

2. Foster RS (2010) Estimated Financial Effects of the 'Patient Protection and Affordable Care Act,as Passed by the US Senate on December 24, 2009. DIANE Publishing.

3. Goodson JD (2010) Patient Protection and Affordable Care Act: promise and peril for primary care. Ann Intern Med 152: 742-4. 